\title{
On the relevance of a testing algorithm for the detection of ROS1-rearranged lung adenocarcinomas
}

\author{
Lénaïg Mescam-Mancini a,b, Sylvie Lantuéjoul ${ }^{\mathrm{a}, \mathrm{b}, \mathrm{d}}$, Denis Moro-Sibilot ${ }^{\mathrm{c}, \mathrm{d}}$, \\ Isabelle Rouquette $^{\mathrm{e}}$, Pierre-Jean Souquet ${ }^{\mathrm{f}}$, Clarisse Audigier-Valette ${ }^{\mathrm{g}}$, \\ Jean-Christophe Sabourin $^{\mathrm{h}}$, Chantal Decroisette $^{\mathrm{i}}$, Linda Sakhri ${ }^{\mathrm{c}}$, \\ Elisabeth Brambilla ${ }^{\mathrm{a}, \mathrm{d}}$, Anne McLeer-Florin ${ }^{\mathrm{a}, \mathrm{b}, \mathrm{d}, *}$
}

a Département d'Anatomie et Cytologie Pathologiques, Pôle de Biologie et Pathologie, CHU Grenoble, France

b Plateforme de Génétique Moléculaire des Tumeurs, Pôle de Biologie et Pathologie, CHU Grenoble, France

c Pôle de médecine aigue communautaire, Unité d'oncologie thoracique, CHU Grenoble, France

d INSERM U 823-Institut A Bonniot-Université J Fourier, Grenoble, France

e Département d'Anatomie et Cytologie Pathologiques, CHU Toulouse, France

${ }^{f}$ Servie de Pneumologie, $\mathrm{CH}$ Lyon Sud, France

g Service de Pneumologie, CH Toulon, France

h Département d'Anatomie et Cytologie Pathologiques, CHU Rouen, France

i Service de Pneumologie, Centre Hospitalier de la Région d'Annecy, Annecy, France

\section{A R T I C L E I N F O}

\section{Article history:}

Received 5 September 2013

Received in revised form

19 November 2013

Accepted 24 November 2013

\section{Keywords:}

ROS1

FISH

Immunohistochemistry

Lung adenocarcinoma

Testing algorithm

Targeted therapy

\begin{abstract}
A B S T R A C T
Objectives: ROS1 proto-oncogene translocations define a new molecular subgroup in non-small cell lung cancers (NSCLC) and are associated with a response to the MET/ALK inhibitor, crizotinib. These rearrangements are described in 0.9-1.7\% NSCLC, in wild-type EGFR, KRAS and ALK ("triple negative") lung adenocarcinomas. Rapid and efficient identification of these alterations is thus becoming increasingly important.

Materials and methods: In this study, 121 triple negative lung adenocarcinomas were screened by both IHC with the ROS1 D4D6 antibody, and FISH using two commercially available ROS1 break-apart probes. To address a possible cross-reactivity of the ROS1 antibody with other protein kinase receptors, we screened 80 additional cases with known EGFR, KRAS, PI3KCA, BRAF, HER2 mutations or ALK-rearrangement.

Results: We diagnosed 9 ROS1-rearranged adenocarcinomas, with both a positive FISH result (51-87\% rearranged nuclei) and a positive IHC staining (2+/3+ cytoplasmic staining). Only one of the ROS1-positive FISH cases was characterized by a classical split pattern, the others showed a variant pattern, most commonly involving a loss of the $5^{\prime}$ telomeric probe. Considering a positivity threshold of $2+$ stained cells, the sensitivity of the ROS1 D4D6 antibody compared to FISH was $100 \%$ and the specificity $96.9 \%$, as two HER2-mutated tumors were positive with D4D6 antibody, without any translocation in FISH. All the ROS1-positive cases were at an advanced stage, arising in never or light smokers. They were mainly solid cribriform and acinar adenocarcinomas, with signet ring cells noted in 5 cases, and calcifications in 3 cases. One positive case was an invasive mucinous carcinoma.

Conclusion: Our results show that a screening algorithm based on an IHC detection of ROS1 fusion proteins, confirmed if positive or doubtful by a ROS1 break-apart FISH assay, is pertinent in advanced "triple negative" lung adenocarcinomas, since the prevalence of ROS1-positive cases in this selected population reaches $7.4 \%$ in our series.
\end{abstract}

(C) 2013 Elsevier Ireland Ltd. All rights reserved.
Abbreviations: ROS1, c-ros oncogene-1; ALK, anaplastic lymphoma kinase; EGFR, epidermal growth factor receptor; KRAS, v-Ki-ras2 Kirsten rat sarcoma viral oncogene homolog; FISH, fluorescent in situ hybridization; IHC, immunohistochemistry.

* Corresponding author at: Plateforme hospitalière de Génétique Moléculaire des Tumeurs, Département d'anatomie et cytologie pathologiques, Pôle de Biologie et de Pathologie, CHU A Michallon, CS 1021738043 Grenoble Cedex 9, France. Tel.: +33 476766338; fax: +33 476765949.

E-mail address: AFlorin@chu-grenoble.fr (A. McLeer-Florin).

\section{Introduction}

Lung cancer remains the leading cause of death by cancer worldwide. However, in addition to the most common mutations involving the EGFR and KRAS genes, driver mutations/rearrangements involving more than 10 other genes have been found in $60 \%$ of non-small cell lung carcinomas (NSCLCs) [1], allowing a further subdivision of NSCLCs into clinically relevant molecular subgroups. Rapid and efficient identification of genetic 
alterations, and in particular of druggable ones, is thus becoming increasingly important for the treatment of NSCLC patients. Out of these are the recently described ROS1 (c-ros oncogene 1, located at 6q22) gene rearrangements. The ROS1 gene encodes a receptor tyrosine kinase of the insulin receptor family. No ROS1 ligand has been identified to date but cellular attachment via its extracellular domain could trigger ROS1 kinase activation [2,3]. Although ROS1 protein expression has been evidenced in various tissues, normal lung tissue seems devoid of ROS1 expression [4]. In a similar way to ALK aberrant kinase activity, ROS1 kinase alterations lead to activated downstream signaling of several oncogenic pathways controlling cell proliferation, survival and cell cycling (STAT3, PI3K/AKT/mTOR, RAS-MAPK/ERK pathways) [5,6]. Historically, ROS1 rearrangements were identified in glioblastomas [7,8], and more recently in NSCLC cell lines and patients, where ROS1 fusions lead to a constitutive activation of the kinase [9-17]. The first two major papers $[9,15]$ described ROS1 rearrangements in 0.9-1.7\% NSCLC cases and, remarkably, only in wild-type EGFR, KRAS and ALK ("triple negative") lung adenocarcinomas (ADC). Promising results show ROS1 fusions in NSCLC are associated with sensitivity to the ALK/MET inhibitor crizotinib, as well as to other small-molecule ROS1 inhibitors [6,18-20].

In this study, we used our previously described testing algorithm for the screening of potential ALK-rearranged tumors [21] to test "triple-negative" (wild-type EGFR, KRAS and ALK) adenocarcinomas for ROS1 rearrangements. We diagnosed by break-apart FISH using commercial probes and by IHC nine ROS1-positive tumors out of 121 patients, tested by both ROS1 IHC and FISH, leading to a proportion of $7.4 \%$ ROS1-positive patients in this selected population $[4,9,15]$.

\section{Materials and methods}

From June 2012 to June 2013, 121 specimens of primary lung adenocarcinomas, classified according to the 2004 WHO classification of lung tumors [22] were sent to the Grenoble University Hospital Genetics and Molecular Platform. These specimens were formalin-fixed and paraffin-embedded. They included small biopsies (bronchial, transthoracic) and surgical specimens (lung resections, lymph node, pleural surgical biopsies). All of them were EGFR and KRAS wild-type and showed no ALK rearrangement, as assessed by IHC and FISH. When needed, IHC stainings for p63 (clone 4A4, Dako, Glostrup, Denmark) and TTF-1 (clone 8G7G3/1 Neomarkers, Fremont, CA, USA) were performed. Clinical data from patients with ROS1-rearranged tumors were collected, including their smoking status, TNM/tumor staging, therapy, and tumor response to therapy. In addition, in order to address a possible cross-reactivity of the ROS1 antibody with other protein kinase receptors, 80 additional cases were investigated by D4D6 ROS1 IHC: 17 ALK-rearranged, 6 HER2-, 7 BRAF-, 6 PI3KCA-, 20 KRAS-, and 24 EGFR-mutated lung adenocarcinomas.

\subsection{ROS1 FISH}

FISH was performed on unstained 3-4 $\mu \mathrm{m}$ formalin-fixed paraffin embedded (FFPE) tumor tissue sections with the use of a ROS1 break-apart probe set using a paraffin pretreatment reagent kit (Vysis, Abbott Laboratories, Abbott Park, IL, USA), as described previously [21]. Two commercially available ROS1 break-apart FISH probe sets were used for this study: the Aquarius Pathology ROS1 Breakapart Probe (Cytocell, Cambridge, GB) and/or the ZytoLight ${ }^{\circledR}$ SPEC ROS1 Dual Color Break Apart Probe, (ZytoVision, Bremerhaven, Germany). The Aquarius Pathology probe set consists of a green $406 \mathrm{~Kb} 5^{\prime}$ (telomeric) probe and two red $(299 \mathrm{~Kb}$ and $171 \mathrm{~Kb}) 3^{\prime}$ (centromeric) probes, positioned on each side of the ROS1 gene, whereas the Zytolight probe mix contains an orange $450 \mathrm{~Kb}$ $5^{\prime}$ probe and a green $750 \mathrm{~Kb} 3^{\prime}$ probe. Both probes were tested on the ROS1-rearranged HCC78 cell line and on ROS1-positive patient samples and yielded similar results. Nuclei were counterstained with DAPI/Vectashield (Vektor Laboratories, Burlingame, CA, USA) and were analyzed with a Metafer slide scanning system (Metasystems, Altlussheim, Germany) under a $63 \times$ oil immersion objective with a fluorescence microscope (Imager Z2, Zeiss) equipped with appropriate filters, a charge-coupled device camera, and the FISH imaging and capturing software Metafer 4 (Metasystems). Signals were enumerated with the ISIS imaging system (Metasystems). Tumor tissues were considered ROS1 FISH positive (ROS1-rearranged) if $>15 \%$ tumor cells showed split red and green signals (signals separated by $\geq 1$ signal diameter) and/or single $3^{\prime}$ signals. Otherwise the samples were considered as FISH negative.

\subsection{ROS1 immunohistochemistry}

Sections were deparaffinized and incubated with the rabbit primary monoclonal ROS1 antibody [4] (Clone D4D6, \#3287, Cell Signaling Technology, Danvers, MA, USA) at a dilution of 1:50 $2 \mathrm{~h}$ at $20^{\circ} \mathrm{C}$. A standard three-stage indirect immunoperoxidase technique was performed on a Benchmark XT Ventana staining module using an XT UltraView DAB kit; antigen retrieving was performed with the Cell Conditioning buffer (CC1, Tris/Boric acid/EDTA pH8.0) for $1 \mathrm{~h}$, according to the manufacturer's instructions (Ventana, Tucson, AZ, USA). No signal amplification was required. The specificity of the ROS1 antibody was assessed by using paraffin-embedded cell blocks of the ROS1-rearranged cell line HCC78, which was subsequently used as positive external controls for all tests. Normal lung tissues were used as negative controls. The percentage of positive cells was evaluated, and staining scores were assessed as follows: 0 ; no staining, $1+$; faint cytoplasmic staining, 2+; moderate cytoplasmic staining and $3+$; intense granular cytoplasmic staining, similarly to previously described [21]. Membrane staining was recorded when observed.

\section{Results}

\subsection{ROS1 fluorescence in situ hybridization (Fig. 1)}

Among the 121 cases analyzed by both immunohistochemistry and FISH, 9 cases were ROS1-rearranged, 98 cases were negative and 14 were not interpretable.

Out of the nine ROS1-rearranged specimens, only one showed a classical split pattern (Fig. 1B), 6 had a ROS1 rearrangement which resulted in the deletion of the $5^{\prime}$ region (nuclei with isolated $3^{\prime}$ signals, Fig. 1C and D), and 2 had a mix pattern (presence of various isolated $3^{\prime}$ and split signals, Fig. 1E). The mean percentage of positive nuclei was $67 \%$ (range: $51-87 \%$ ); the total number of tumor nuclei analyzed ranged from 83 to 244 , with a mean of 137 .

For the 98 negative cases, as with ALK FISH [21,23], nuclei showed various patterns within a given tumor; nuclei with 1 to more than 6 fusions, and/or isolated green and/or red signals, and/or split signals (Fig. 1A). 34 cases (34.7\%) showed two fusion signals or very close green and red signals in the majority of nuclei (predominant pattern). In 9 cases, the presence of 3-5 fused ROS1 signals was the predominant pattern in tumor nuclei and in 32 cases loss of one ROS1 fusion signal (only 1 gene copy) was the predominant pattern. In addition, 1 case showed $15 \%$ or more nuclei with at least 6 ROS1 fusion signals.

For all ROS1-non rearranged cases, mean percent of positive nuclei (percent of nuclei showing a rearrangement pattern in ROS1negative cases) was $3.2 \%$, ranging from 0 to $11.8 \%$. 

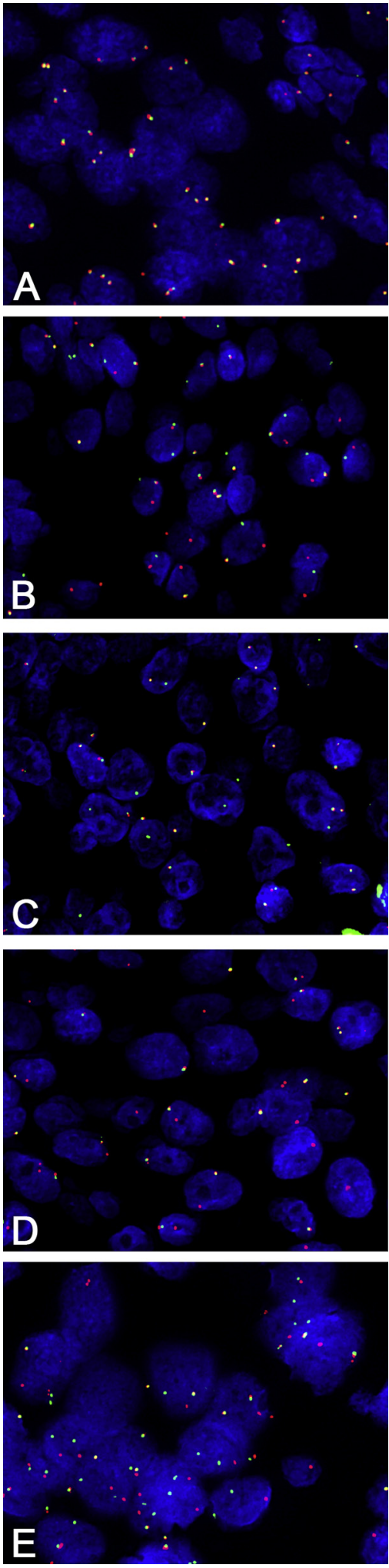

Fig. 1. Detection of ROS1 gene rearrangements in triple negative lung adenocarcinoma cases by FISH. Non-rearranged ROS1 (A) shows fusion (orange signals) or very close apposition of the probes close to the $3^{\prime}$ and the $5^{\prime}$ ends of the gene. $A, B, C$ and $E$ : tumor nuclei hybridized with the ZytoLight ${ }^{\circledR}$ SPEC ROS1 dual color beak-apart probe (ZytoVision). Rearranged ROS1 is indicated by split $3^{\prime}$ (green) and $5^{\prime}$ (red) signals $(B)$ or isolated $3^{\prime}$ (green) signals (C) or various single $3^{\prime}$ and split signals $(E)$. D: tumor nuclei hybridized with the Aquarius ${ }^{\circledR}$ ROS1 dual color beak-apart probe (Cytocell). Rearranged ROS1 appears here as isolated red $\left(3^{\prime}\right)$ signals. Original magnification $630 \times$. (For interpretation of the references to color in this figure legend, the reader is referred to the web version of this article.)
Table 1

ROS1 fusion protein detection by IHC in a panel of lung adenocarcinoma FFPE samples with mutated or rearranged protein kinase genes.

\begin{tabular}{lllc}
\hline $\begin{array}{l}\text { Protein kinase gene alteration } \\
N=80, \text { all ROS1 FISH negative }\end{array}$ & $\begin{array}{l}\text { ROS1 IHC } \\
\text { positive }\end{array}$ & $\begin{array}{l}\text { ROS1 IHC } \\
\text { doubtful }\end{array}$ & $\begin{array}{l}\text { ROS1 IHC } \\
\text { negative }\end{array}$ \\
\hline ALK $(n=17)$ & 1 & 0 & 16 \\
$\operatorname{HER} 2(n=6)$ & 3 & 0 & 3 \\
$\operatorname{BRAF}(n=7)$ & 0 & 0 & 7 \\
PI3KCA $(n=6)$ & 0 & 0 & 6 \\
KRAS $(n=20)$ & 0 & 0 & 20 \\
EGFR $(n=24)$ & 0 & 2 & 22 \\
\hline
\end{tabular}

Fourteen cases were not interpretable Thirteen cases showed no or very weak hybridization signals and a high background staining, most probably due to inappropriate preanalytical steps (poor quality of the material, decalcification, delays in fixation, etc.). One case was not interpretable due to an insufficient number of tumor cells analyzable (31 cells, all showing no ROS1 gene rearrangement).

\subsection{ROS1 immunohistochemistry (Fig. 2)}

\subsubsection{ROS1 protein expression in ROS1-positive HCC78 cell line} and normal human lung tissue

As described initially by Rimkunas et al. [4], HCC78 cells showed a strong cytoplasmic and punctate staining. In a few specimens of normal lung tissue, rare pneumocytes were slightly stained and nonspecific positivity of macrophages and in particular giant cells was noted (Fig. 2A and B).

\subsubsection{ROS1 fusion protein detection in EGFR, KRAS and ALK-non mutated/rearranged lung adenocarcinomas}

All nine ROS1 FISH-positive cases showed ROS1 protein immunostaining. In these tumors, the cytoplasmic staining was at least moderate $(2+)$, in more than $40 \%$ of cells, with an additional intense signal (3+) in 2 cases (Fig. 2C). Positive stainings were heterogeneous, with tumor cells faintly to intensely stained and some cells showing no staining. ROS1 immunostaining was cytoplasmic for all cases, with a membrane reinforcement noted in two cases, and a perivacuolar cytoplasmic positivity in signet ring cells. A striking granular cytoplasmic staining with perinuclear dots was observed in one case (Fig. 2D).

Out of the 98 FISH-negative specimens, 95 did not express ROS1 protein. Two of the ROS1 FISH-negative specimens had a positive IHC result with tumor cells stained with $2+$ to $3+$ intensities and interestingly, both were HER2-mutated. The last specimen showed a doubtful ROS1 immunostaining result with 80 cells stained with a $1+$ intensity.

One case, containing only 20 tumor cells, was characterized by a moderate staining of all cells; unfortunately ROS1 FISH analysis was not interpretable due to the absence of hybridization signals and the patient did not agree to repeat the trans-thoracic biopsy, having previously suffered from a pneumothorax.

\subsubsection{ROS1 fusion protein detection in ALK-rearranged, HER2-, BRAF-, PI3KCA-, KRAS-, or EGFR-mutated lung adenocarcinomas (Table 1)}

Out of the 17 ALK-rearranged cases analyzed, one was ROS1 IHC-positive, showing a moderate staining in $30 \%$ of cells, and a faint staining in $40 \%$ of cells. Out of the 6 HER2-mutated adenocarcinomas, 3 were ROS1 IHC-positive with $30-40 \%$ of cells stained with a 2+ intensity. There was no ROS1 expression in tumors showing a BRAF mutation ( 7 cases), a PIK3CA mutation (6 cases), or a KRAS mutation (20 cases). Out of the 24 cases harboring an EGFR mutation (mutation in exons $18 / 20 / 21$ or deletion in exon 19 ), a doubtful faint staining was observed in $15 \%$ of cells in 2 cases, both of which had a mutation in exon 21 . The HER2-mutated $(n=3)$ and 

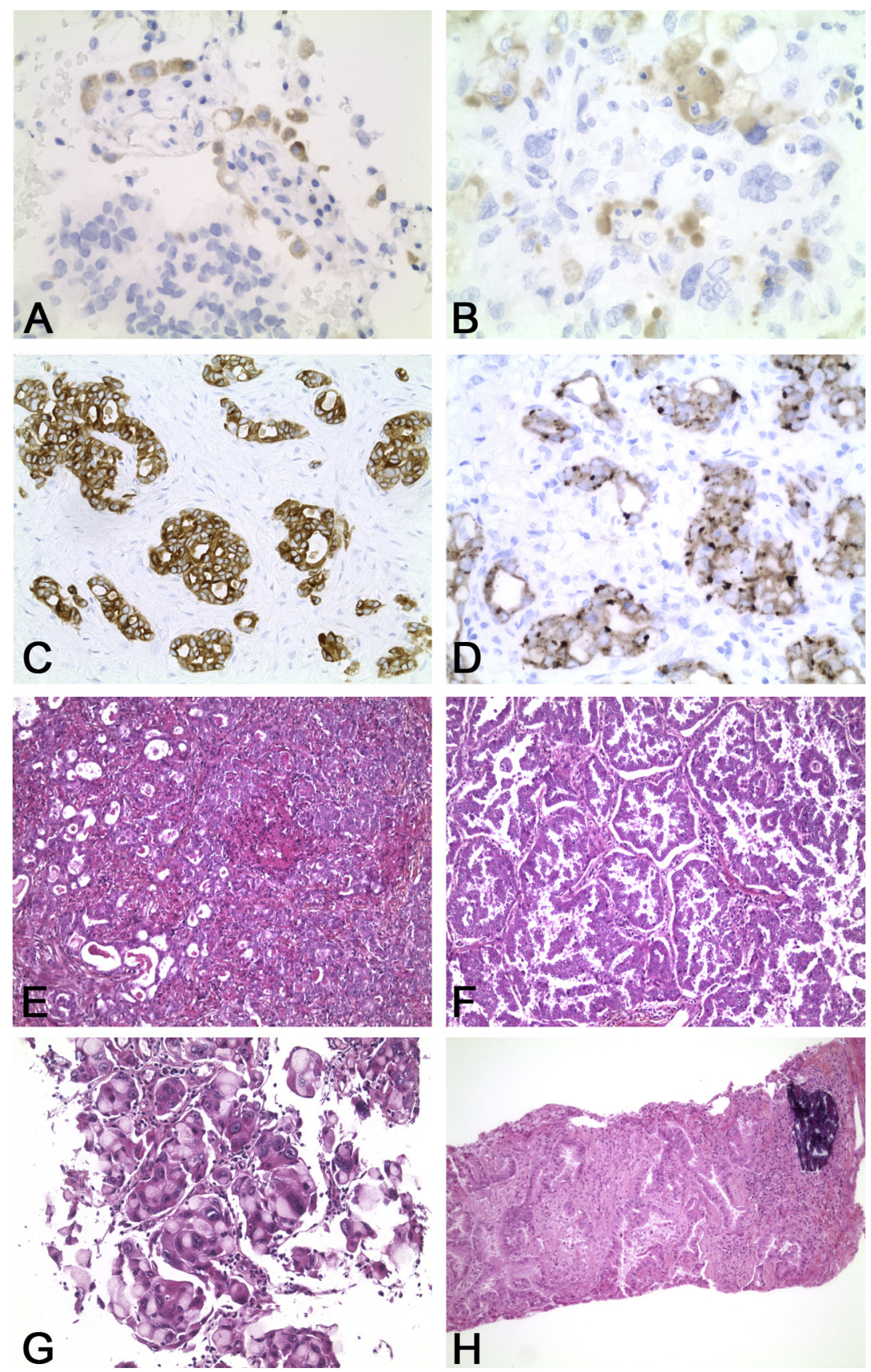

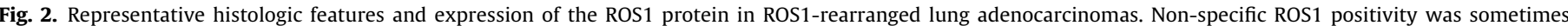

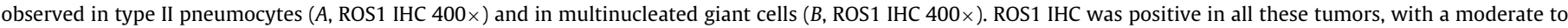

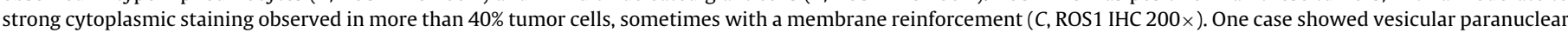

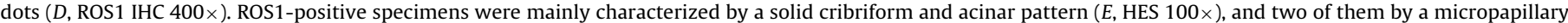
pattern $(F$, HES $100 \times)$. Signet ring cells were noted in 5 cases (G, HES $200 \times)$, and calcifications in 3 cases $(H$, HES $100 \times)$.

ALK-rearranged $(n=1)$ tumors showing a ROS1 positive staining by IHC, as well as the EGFR-mutated tumors $(n=2)$ showing a doubtful ROS1 immunostaining, were all ROS1 FISH-negative.

In summary, considering a positivity threshold of 2+ staining intensity, the sensitivity of the ROS1 D4D6 antibody compared to FISH in this study is $100 \%$ and the specificity is $96.9 \%$ (Table 2 ).

\subsection{Correlation between ROS1 rearrangement and clinical and histological data (Tables 3 and 4)}

ROS1 positive patients' mean age was 60.9 years ( $41-78$ years), 5 patients were female and 4 male. ROS1 negative patients' mean
Table 2

Correlation between ROS1 FISH and IHC results.

\begin{tabular}{llll}
\hline$N=121$ & $\begin{array}{l}\text { FISH positive, } \\
n=9\end{array}$ & $\begin{array}{l}\text { FISH negative, } \\
n=98\end{array}$ & $\begin{array}{l}\text { FISH not interpretable, } \\
n=14\end{array}$ \\
\hline $\begin{array}{l}\text { IHC positive } \\
(2+/ 3+) n=11\end{array}$ & $9 / 9$ & $\begin{array}{l}2 / 98(\text { HER } 2 \\
\text { mutated })\end{array}$ & 0 \\
$\begin{array}{l}\text { IHC doubtful } \\
(1+) n=2\end{array}$ & 0 & $1 / 98$ & $1 / 14$ \\
$\begin{array}{l}\text { IHC negative } \\
n=108\end{array}$ & 0 & $95 / 98$ & $13 / 14$ \\
\hline
\end{tabular}


Table 3

Correlation between ROS1-rearrangement and clinical data.

\begin{tabular}{|c|c|c|c|c|c|c|}
\hline Patient & Sex & Age at diagnosis & TNM & Stage & Smoking habit & Specimen \\
\hline 1 & M & 41 & T4N2M0 & IIIa & Non smoker & Transthoracic needle biopsy \\
\hline 2 & $\mathrm{~F}$ & 49 & T2aN3M1 & IV & Non smoker & Transthoracic needle biopsy \\
\hline 3 & M & 50 & T3N2M1 & IV & Non smoker & Pleural biopsy \\
\hline 4 & $\mathrm{~F}$ & 71 & T3N2M1b & IV & Non smoker & Mediastinal lymph node \\
\hline 5 & M & 61 & T4NOMO & IIIb & Non smoker & Lung resection \\
\hline 6 & $\mathrm{~F}$ & 78 & T1aN2M0 & IIIa & Non smoker & Lung resection \\
\hline 7 & $\mathrm{~F}$ & 58 & $\mathrm{~T} 2 \mathrm{bN} 3 \mathrm{M} 0$ & IIIb & Non smoker & Bronchial biopsy \\
\hline 8 & M & 64 & T2 N2 M1 & IV & Ex-smoker 2,5 pack-year & Cervical lymph node \\
\hline 9 & $\mathrm{~F}$ & 76 & T3N2M1 & IV & Non smoker & Pleural biopsy \\
\hline
\end{tabular}

Table 4

Correlation between ROS1-rearrangement and histological data.

\begin{tabular}{|c|c|c|c|c|c|}
\hline Patient & Predominant pattern & Other histological element & ROS1 IHC & ROS1 FISH pattern & Number of rearranged nuclei \\
\hline 1 & Invasive mucinous & Calcification & $1+: 10 \% ; 2+: 90 \%$ & Split & $87 \%(130 / 150)$ \\
\hline 2 & Solid (cribriform) and acinar & No & $1+: 50 \% ; 2+: 40 \%{ }^{\mathrm{a}}$ & $5^{\prime}$ deletion & $66 \%(69 / 104)$ \\
\hline 3 & Acinar and solid (cribriform) & Calcification, signet ring cells $<10 \%$ & $1+: 30 \% ; 2+: 50 \%$ & $5^{\prime}$ deletion & $71 \%(116 / 164)$ \\
\hline 4 & Solid and acinar & Signet ring cells $<10 \%$ & $1+: 60 \% ; 2+: 40 \%{ }^{\mathrm{a}}$ & $5^{\prime}$ deletion & $83 \%(96 / 116)$ \\
\hline 5 & Micropapillary and papillary & No & Not interpretable & $5^{\prime}$ deletion & $55 \%(58 / 105)$ \\
\hline 6 & Solid (cribriform) and acinar & Calcification & $2+: 80 \%$ with perinuclear dot & $5^{\prime}$ deletion & $66 \%(92 / 140)$ \\
\hline 7 & Solid & Signet ring cells $>10 \%$ & $1+: 30 \% ; 2+: 40 \%$ & $5^{\prime}$ deletion & $54 \%(45 / 83)$ \\
\hline 8 & Micropapillary & No & $1+: 40 \% ; 2+: 40 \% ; 3+: 20 \%$ & Split and $5^{\prime}$ del, polysomia & $69 \%(168 / 244)$ \\
\hline 9 & Solid (cribriform) and acinar & Signet ring cells $<10 \%$ & $3+: 90 \%$ & $5^{\prime}$ deletion & $51 \%(46 / 90)$ \\
\hline
\end{tabular}

a With membrane reinforcement.

age was 62.3 years (31-88 years), 46 were female and 56 male. Out of the nine positive patients, eight were non-smokers with, for one of them, a passive exposure to tobacco smoke. Only one patient was a former light-smoker (2.5 packs/years). Five patients were at stage IV, two were at stage IIIb and two were at stage IIIa at the time of the ROS1-rearrangement diagnosis. Three patients had lung surgery. Five patients had a partial response under pemetrexed alone or associated with a platinum compound, one had a stable disease under pemetrexed alone. After tumor progression under pemetrexed, two patients were included in a crizotinib expanded access program, with a partial response ( $\geq 50 \%$ at 2 months), but with a dose reduction for one of them, due to toxicity (bilateral pleurisy, severe leg edema, facial erythroderma). One of these two crizotinibtreated patients progressed after 5 months, suggesting a secondary resistance. One patient, treated by carboplatin and vinorelbine, died 2 years after his initial diagnosis of lung cancer.

Specimens were either surgical lung resections (2 cases), or pleural biopsies (2), lymph node biopsies (2), bronchial biopsies (1) or trans-thoracic fine-needle biopsies (TTFNB) (2). The median percentage of malignant cells was 60\%. ROS1-positive adenocarcinomas were solid and acinar in 7 cases (78\%), with an associated cribriform pattern in 4 cases (44\%) (Fig. 2E), and a lepidic architecture was also associated in one case. One lung resection showed a micropapillary and papillary pattern. For one case, the lung resection showed a solid, acinar, micropapillary and lepidic adenocarcinoma, the corresponding synchronous lymph node metastasis was only micropapillary (Fig. 2F). Interestingly, one case was a mucinous invasive adenocarcinoma, diagnosed through a TTNB. Signet ring cells were noted in 4 cases (representing less than $10 \%$ of tumor cells in 3 cases, and 20\% in 1 case) (Fig. 2G). No extracellular mucus was found, but, interestingly, calcifications were noted in 3 cases (in the lumen of cribriform formations or in the stroma) (Fig. $2 \mathrm{H}$ ).

All ROS1-positive tumors were TTF1 positive, with a heterogeneous staining (from $1+$ in $40 \%$ of cells to $3+$ in $90 \%$ of cells). P63 expression was moderate in 2 cases ( $40 \%$ and $60 \%$ ), negative in all other cases.

\section{Discussion}

By using both ROS1 IHC and FISH, we identified 9 patients with ROS1-rearranged lung adenocarcinomas, leading to a prevalence of $7.4 \%$ in an enriched cohort of 121 "triple-negative" cases. This study is the third one addressing ROS1 fusion detection in Caucasian patients, 70 ROS1-fused NSCLC cases out of 84 having been reported in Asian patients to date $[4,6,9,10,12,14-16]$.

Eight of our ROS1-positive patients were non-smokers, and one was a former light-smoker (2.5 PY), consistent with the previously described higher prevalence of ROS1-positive-NSCLCs in non-smokers $[9,15]$. ROS1-positive patients' mean age was around 61 years, not different from ROS1-negative patients (mean age 62.3 years), in accordance with the studies of Yoshida et al. [16] and Kim et al. [12], but not with another series in which ROS1-positive patients were found to be twelve years younger than negative patients [9].

There was no gender-predominance in our series. Interestingly, considering all the ROS1-positive cases published to date, 50 out of 71 documented cases were described in women [6,9,10,12,14-16]. However, as most were from Asia, there is a need for further epidemiological studies on Caucasian populations [24].

Among the ROS1-positive patients we detected, 6 had a partial response or a stable disease with pemetrexed, 2 had a partial response with crizotinib, but one of them progressed, developing a probably secondary resistance after 5 months of crizotinib (the mechanism of resistance is currently under investigation). As this is a prospective study, longer clinical outcome and survival data are not yet available. However, our observations are concordant with the promising results of clinical trials evaluating the sensitivity of ROS1-rearranged tumors to pemetrexed and crizotinib $[19,20,25,26]$.

Histologically, ROS1-rearranged tumors did not exhibit a specific morphological pattern; they were predominantly solid and acinar, and a focal cribriform aspect was associated in $44 \%$ of cases, without mucinous features. Signet ring cells were found in five cases, representing more than $10 \%$ of tumor cells in one case. Compared to ALK-rearranged adenocarcinomas, the presence of a cribriform pattern and of signet ring cells seems lower in ROS1+ tumors [21,27,28], but, similarly to ALK-rearranged tumors [27], calcifications were noted in nearly one third of our cases.

Considering a positivity threshold for ROS1 IHC of 2+ staining intensity, all ROS1 FISH-positive tumors were positive by IHC. The intensity and the distribution of the immunostainings were heterogeneous, with a cytoplasmic granular stain, sometimes associated 
with a membrane reinforcement, as seen with ALK fusion-protein staining in solid tumors [21]. A striking staining pattern with positive perinuclear dots was observed in one case, which could correspond to a FIG-ROS1 fusion protein, as a deletion of the 5 probe was observed by FISH in this tumor $[4,8]$.

In our hands, the D4D6 ROS1 antibody was positive in 4 ROS1 FISH-negative cases harboring an ALK (1 case) or HER2 rearrangement/mutation (3 cases), suggesting that the D4D6 clone recognizes an epitope present on one or several common protein(s) involved in ALK, HER2 and ROS1 signaling pathways. Of note, a recent paper by Lee et al. also suggests a possible (over)expression of the ROS1 protein, which could occur through epigenetics mechanisms, such as promotor hypomethylation, without any gene translocation [29]. This phenomenon could perhaps explain the faint positivity of ROS1 immunostaining in some FISH-negative cases. In view of these results, we recommend looking for HER2 mutations for all ROS1 FISH-negative cases showing a positive ROS1 IHC.

Despite its limitations (cost, limited tissue and cell morphology, signal fading), FISH remains the gold standard technique, and its clear advantage over alternative techniques (RT-PCR, sequencing technologies, etc.) is its ability to detect a translocation, whatever the fusion partner, as at least 9 different partners have been described for ROS1. Interestingly, the predominant ROS1+ FISH pattern obtained was not the classical split pattern (observed in only one specimen), but a $5^{\prime}$ deletion, sometimes associated with split signals and/or polysomy, suggesting, as previously discussed [16], that ROS1 fusions develop through complex genomic events associating deletion, insertion and copy number gains. In addition, these FISH patterns do not seem to be related to the fusion partner [16], and studies are needed to compare FISH patterns and fusion variants to tyrosine-kinase inhibitor response.

\section{Conclusion}

In conclusion, given the prevalence of ROS1 fusions in up to $7.4 \%$ EGFR, KRAS and $A L K$ non-mutated/rearranged adenocarcinomas, we recommend a prescreening by ROS1 IHC of these "triple-negative" tumors, followed by FISH in positive or doubtful cases or when the clinical and histopathological presentation are suggestive of a ROS1 rearrangement. We also recommend testing for HER2 mutations all cases with a positive ROS1 IHC and a negative ROS1 FISH.

\section{Conflict of interest statement}

None declared.

\section{Acknowledgements}

The authors wish to thank Régine Bethier, Corine Cadet, Françoise Ceccaldi and Laurence David-Boudet for their excellent technical assistance.

This project received funding from the French Institut National du Cancer (INCa), and the European Community's Seventh Framework Programme (FP7/2007-2013) under grant agreement $\mathrm{n}^{\circ}$ 258677 - CURELUNG Project.

\section{References}

[1] Cardarella S, Johnson BE. The impact of genomic changes on treatment of lung cancer. Am J Respir Crit Care Med 2013;188:770-5.

[2] Acquaviva J, Wong R, Charest A. The multifaceted roles of the receptor tyrosine kinase ROS in development and cancer. Biochim Biophys Acta 2009;1795:37-52
[3] El-Deeb IM, Yoo KH, Lee SH. ROS receptor tyrosine kinase: a new potential target for anticancer drugs. Med Res Rev 2011;31:794-818.

[4] Rimkunas VM, Crosby KE, Li D, Hu Y, Kelly ME, Gu TL, et al. Analysis of receptor tyrosine kinase ROS1-positive tumors in non-small cell lung cancer: identification of a FIG-ROS1 fusion. Clin Cancer Res 2012;18:4449-57.

[5] Chin LP, Soo RA, Soong R, Ou SH. Targeting ROS1 with anaplastic lymphoma kinase inhibitors: a promising therapeutic strategy for a newly defined molecular subset of non-small-cell lung cancer. J Thorac Oncol 2012;7:1625-30.

[6] Davies KD, Doebele RC. Molecular pathways: ROS1 fusion proteins in cancer. Clin Cancer Res 2013;19:4040-5.

[7] Birchmeier C, Sharma S, Wigler M. Expression and rearrangement of the ROS1 gene in human glioblastoma cells. Proc Natl Acad Sci USA 1987;84:9270-4

[8] Charest A, Lane K, McMahon K, Park J, Preisinger E, Conroy H, et al. Fusion of FIG to the receptor tyrosine kinase ROS in a glioblastoma with an interstitial del(6)(q21q21). Genes Chromosomes Cancer 2003;37:58-71.

[9] Bergethon K, Shaw AT, Ou SH, Katayama R, Lovly CM, McDonald NT, et al. ROS1 rearrangements define a unique molecular class of lung cancers. J Clin Oncol 2012;30:863-70

[10] Cai W, Li X, Su C, Fan L, Zheng L, Fei K, et al. ROS1 fusions in Chinese patients with non-small-cell lung cancer. Ann Oncol 2013;24:1822-7.

[11] Govindan R, Ding L, Griffith M, Subramanian J, Dees ND, Kanchi KL, et al. Genomic landscape of non-small cell lung cancer in smokers and neversmokers. Cell 2012;150:1121-34.

[12] Kim HR, Lim SM, Kim HJ, Hwang SK, Park JK, Shin E, et al. The frequency and impact of ROS1 rearrangement on clinical outcomes in never smokers with lung adenocarcinoma. Ann Oncol 2013;24:2364-70

[13] Seo JS, Ju YS, Lee WC, Shin JY, Lee JK, Bleazard T, et al. The transcriptional landscape and mutational profile of lung adenocarcinoma. Genome Res 2012;22:2109-19.

[14] Sholl LM, Sun H, Butaney M, Zhang C, Lee C, Janne PA, et al. ROS1 immunohistochemistry for detection of ROS1-rearranged lung adenocarcinomas. Am J Surg Pathol 2013;37:1441-9.

[15] Takeuchi K, Soda M, Togashi Y, Suzuki R, Sakata S, Hatano S, et al. RET ROS1 and ALK fusions in lung cancer. Nat Med 2012;18:378-81.

[16] Yoshida A, Kohno T, Tsuta K, Wakai S, Arai Y, Shimada Y, et al. ROS1-rearranged lung cancer: a clinicopathologic and molecular study of 15 surgical cases. Am J Surg Pathol 2013;37:554-62.

[17] Rikova K, Guo A, Zeng Q, Possemato A, Yu J, Haack H, et al. Global survey of phosphotyrosine signaling identifies oncogenic kinases in lung cancer. Cell 2007;131:1190-203.

[18] Kwak EL, Bang YJ, Camidge DR, Shaw AT, Solomon B, Maki RG, et al. Anaplastic lymphoma kinase inhibition in non-small-cell lung cancer. N Engl J Med 2010;363:1693-703.

[19] Shaw A, Camidge DR, Engelman JA, Solomon B, Kwak EL, Clark JW, et al. Clinical activity of crizotinib in advanced non-small cell lung cancer (NSCLC) harboring ROS1 gene rearrangement. J Clin Oncol, 2012 ASCO Annual Meeting Proceedings 2012;30:7508.

[20] Ou SH, Bang YJ, Camidge DR, Riely GJ, Salgia R, Shapiro GI, et al. Efficacy and safety of crizotinib in patients with advanced ROS1-rearrangement non-small cell lung cancer (NSCLC). J Clin Oncol, 2013 ASCO Annual Meeting Proceedings 2013;31:8032.

[21] McLeer-Florin A, Moro-Sibilot D, Melis A, Salameire D, Lefebvre C, Ceccaldi F, et al. Dual IHC and FISH testing for ALK gene rearrangement in lung adenocarcinomas in a routine practice: a French study. J Thorac Oncol 2012;7: $348-54$.

[22] Travis WD, Brambilla E, Muller-Hermelink HK, Harris CC. World Health Organization classification of tumours. Pathology and genetics of tumours of the lung, pleura, thymus and heart. Lyon: IARC Press; 2004

[23] Camidge DR, Kono SA, Flacco A, Tan AC, Doebele RC, Zhou Q, et al. Optimizing the detection of lung cancer patients harboring anaplastic lymphoma kinase (ALK) gene rearrangements potentially suitable for ALK inhibitor treatment. Clin Cancer Res 2010;16:5581-90.

[24] El-Telbany A, Ma PC. Cancer genes in lung cancer: racial disparities: are there any? Genes Cancer 2012:3:467-80.

[25] Riess JW, Padda SK, Bangs CD, Das M, Neal JW, Adrouny AR, et al. A case series of lengthy progression-free survival with pemetrexed-containing therapy in metastatic non-small-cell lung cancer patients harboring ROS1 gene rearrangements. Clin Lung Cancer 2013;14:592-5.

[26] Awad MM, Katayama R, McTigue M, Liu W, Deng YL, Brooun A, et al. Acquired resistance to crizotinib from a mutation in CD74-ROS1. N Engl J Med 2013:368:2395-401.

[27] Yoshida A, Tsuta K, Nakamura H, Kohno T, Takahashi F, Asamura H, et al. Comprehensive histologic analysis of ALK-rearranged lung carcinomas. Am J Surg Pathol 2011:35:1226-34.

[28] Rodig SJ, Mino-Kenudson M, Dacic S, Yeap BY, Shaw A, Barletta JA, et al. Unique clinicopathologic features characterize ALK-rearranged lung adenocarcinoma in the western population. Clin Cancer Res 2009;15:5216-23.

[29] Lee HJ, Seol HS, Kim JY, Chun SM, Suh YA, Park YS, et al. ROS1 receptor tyrosine kinase, a druggable target, is frequently overexpressed in non-small cell lung carcinomas via genetic and epigenetic mechanisms. Ann Surg Oncol 2013;20:200-8. 